\title{
Literacidad a partir de realidades integradoras
}

\section{Literacy from integrating realities}

\author{
Claudia Romo SabugaL ${ }^{*}$
}

El objetivo de este artículo es mostrar el proceso de construcción y descubrimiento que permitió determinar las características de un método alfabetizador capaz de asegurar un aprendizaje eficaz de la lengua escrita a partir del trabajo con realidades integradoras, mediadas por la reflexión que los docentes pueden emplear en el aula para desarrollar la literacidad. Este aprendizaje se presenta como resultado de un proceso cualitativo de investigación-acción del cual deriva una propuesta que aborda la literacidad como una alternativa para la alfabetización que permite que la experiencia de aprendizaje sea continua, dinámica, lúdica y vinculada a la realidad del niño y la niña.

The purpose of this article is to show the process of construction and discovery allowing determining the characteristics of an alphabetizing method capable to assure an efficient learning of the written language from working with integrating realities, mediated by reflection which teachers can use in classrooms to develop literacy. The learning of the written language through integrating realities is presented as a result of a research-action process from which derives a proposal that approaches literacy as an alternative to alphabetization that allows the learning experience to be continuous, dynamic, playful and linked to the child's reality.

\section{Palabras clave:}

literacidad, lengua escrita, mediación, procesos de aprendizaje

\section{Keywords:}

literacy, written language, mediate, learning processes

Recibido: 30 de junio de 2021| Aceptado para su publicación: 5 de febrero de 2021|

Publicado: 26 de marzo de 2021

Recuperado de: https://sinectica.iteso.mx/index.php/SINECTICA/article/view/1183

doi: 10.31391/S2007-7033(2021)0056-011

\footnotetext{
* Doctora en Socioformación y Sociedad del Conocimiento en el CIFE. Catedrática en el Instituto La Paz, de Querétaro, en la Universidad Mondragón, México. Directora general de Desarrollo y Proyección Humana, SC, centro orientado a la capacitación de docentes, padres de familia y empresas. Líneas de investigación: desarrollo del lenguaje, lectura y escritura, metacognición. Correo electrónico: claudiaromo@live.com.mx/ https://orcid.org/0000-0002-9995-7018
} 


\section{INTRODUCCIÓN}

$7 \mathrm{n}$ los últimos años, las capacidades de leer y escribir han llamado la atención 4 de los sistemas educativos: el de México no es la excepción, incluso los resultados de la prueba Programme for International Student Assessment (PISA, por sus siglas en inglés) para México (OCDE, 2018), aplicada a los estudiantes entre quince y dieciocho años de edad, revelan que solo el $1 \%$ de los alumnos emplean habilidades avanzadas en lectura y comprensión de textos largos. En cuanto al área de lectura (en esta prueba), México obtuvo 420 puntos, cuando el promedio en los países de la Organización para la Cooperación y el Desarrollo Económicos (OCDE, 2018) es de 487 puntos (PISA, 2019).

Estos datos muestran que resulta necesario fortalecer en los estudiantes ambos aprendizajes para asegurar que puedan emplearlos con eficiencia en diferentes ámbitos de su vida; sin embargo, hay que tomar en cuenta que ello se debe a diversos factores, entre los que podemos identificar el contexto familiar, las capacidades individuales, las experiencias escolares a lo largo de su trayectoria académica, las oportunidades de explorar e interactuar con diversos tipos de textos, incluso el proceso a través del cual se aprendió a leer y escribir.

Ante la necesidad de favorecer un sólido aprendizaje y un desempeño eficiente de la lengua escrita en los estudiantes, presentamos este trabajo que ofrece, inicialmente, algunas reflexiones en torno a la realidad del aprendizaje de la lengua escrita en la actualidad, los obstáculos para lograrlo y una revisión de los métodos que se emplean para tal efecto. Profundizamos en el concepto de literacidad, compartimos la metodología a la que recurrimos para el estudio, el procedimiento seguido y las conclusiones.

\section{APRENDIZAJE DE LA LENGUA ESCRITA: UNA VISIÓN ACTUAL}

El favorecer un sólido aprendizaje de estas habilidades que se fortalezca y consolide a lo largo de la vida nace de la preocupación de que las nuevas generaciones valoren y empleen la lectura y la escritura como prácticas indispensables para comunicarse y aprender de manera eficiente y permanente; desarrollar la literacidad constituye una forma de asegurarlo.

Muchos estudiantes han emprendido un proceso de alfabetización bajo la conducción de un profesor que, aplicando uno de los muchos métodos tradicionales, ha generado en ellos un aprendizaje superficial y mecánico de la lengua escrita.

La prueba PISA (2019) definió la competencia lectora como la capacidad del individuo para comprender, emplear, reflexionar e interesarse en los textos escritos a fin de desarrollar sus conocimientos, su potencial personal y su capacidad de participar en la sociedad. Desarrollar la competencia lectora implica lograr un dominio de la lectura en tres dimensiones: textos, situaciones y procesos (PISA, 2019). En esos casos, la lectura y la escritura se integran y abordan una variedad de textos que tienen que ver tanto con el contenido y la forma de presentarlo como con la posibilidad de enfrentar con éxito una gran variedad de tareas y actividades de índole personal y social.

Así, tanto la competencia lectora como la producción de textos reflejan la necesidad de un tratamiento integral del lenguaje que abarque el aspecto comprensivo 
(escuchar y leer) y el productivo (hablar y escribir) para lograr que el individuo sea capaz de emplearlo de manera eficiente no solo en situaciones académicas, sino también con fines personales, profesionales, familiares, sociales y recreativos, entre otros. Como lo menciona Caldera (2003), "en un modelo funcional predomina la competencia comunicativa de la escritura en situaciones específicas de uso: informar, opinar, preguntar, persuadir, entre otros" (p. 364).

La necesidad de asegurar un aprendizaje eficaz de la lengua escrita implica, para los docentes, mucho más que revisarla como objeto de estudio en el aula; supone generar un ambiente de aprendizaje que atrape al niño y al joven y los vincule afectiva y efectivamente con la lectura y la escritura, y desarrolle la competencia lectora en todas sus dimensiones para que les permita comunicarse y desenvolverse mediante la escritura.

En México se han realizado evaluaciones estandarizadas aplicadas por el Instituto Nacional para la Evaluación de la Educación (INEE) al término de los diferentes niveles de la educación obligatoria (preescolar, primaria, secundaria y media superior), cuya finalidad ha sido determinar los niveles de logro de los estudiantes en las áreas de lenguaje, matemáticas y socioemocional. En el caso del campo formativo de lenguaje y comunicación, el INEE tomó como unidades de evaluación (INEE, 2015):

-Comprensión lectora (extracción de información, comprensión global, interpretación y análisis del contenido y la estructura).

- Reflexión sintáctica sobre la lengua (evaluación crítica del texto, reflexión semántica, sintáctica y morfosintáctica, así como de los convencionalismos de la lengua).

-Conocimiento de fuentes de información.

Se esperaba que los alumnos que acudieron a la escuela y fueron alfabetizados lograran desempeñarse en los aspectos citados; sin embargo, los resultados del Plan Nacional para la Evaluación de los Aprendizajes (Planea) (INEE, 2019) revelaron que, de los estudiantes de sexto de primaria que realizaron la prueba, el $49 \%$ se ubicaron en el nivel I, lo que significa un logro insuficiente de los aprendizajes clave del currículo; el 33\%, en el nivel II, que muestra un dominio básico, apenas indispensable de los aprendizajes clave del currículo; el 15\% se colocó en el nivel III; es decir, con un dominio satisfactorio de los aprendizajes clave del currículo; y solo un $3 \%$, en el nivel IV, que tiene un dominio sobresaliente.

Estos resultados exponen la necesidad de fortalecer el aprendizaje de la lengua escrita y atender los diversos factores que influyen en su consolidación, el trabajo en todos los niveles escolares y la promoción de un proceso de alfabetización que pueda asegurar el desarrollo de capacidades en los niños y jóvenes mexicanos para seguir aprendiendo, para participar y comunicarse de manera competente.

\section{OBSTÁCULOS FRENTE AL APRENDIZAJE EFICIENTE DE LA LENGUA ESCRITA}

Las barreras para el aprendizaje y la participación que enfrentan cotidianamente los educandos a lo largo de su escolaridad son muchas, pero, si logran un dominio de la lectura y la escritura, serán menos los obstáculos que deberán enfrentar al contar 
con estas herramientas para comunicarse y aprender de modo permanente. Si los estudiantes consiguen una adquisición eficiente de la lengua escrita, ellos podrán participar en la sociedad como ciudadanos; contribuir a la construcción de una sociedad democrática; acceder a un trabajo productivo y remunerado; defender sus derechos; y acceder a conocimientos científicos y a información compleja contenida en materiales impresos y electrónicos que les permitan interactuar, tomar decisiones, asumir un rol protagónico en la dirección de su destino en lo individual y en lo colectivo, al considerar que el "efecto multiplicador" de la alfabetización empodera a los pueblos, les ayuda a participar en forma plena en la sociedad y contribuye a mejorar la calidad de los medios de subsistencia (Unesco, s.f.).

Un fenómeno actual es el llamado analfabetismo funcional, término recuperado de Hamadache (1976) por Martínez, Trucco y Palma (2014), que se refiere a la condición de aquellas personas que no pueden participar en las actividades en las cuales se requiere adquirir competencias específicas para la actuación eficaz en su grupo y comunidad y que les permiten continuar usando la lectura, la escritura y la aritmética al servicio de su propio desarrollo y del de su comunidad.

Para reducir el analfabetismo funcional, es crucial lograr una alfabetización funcional que en verdad empodere a los individuos a través de sus procesos educativos, ya que, como señalan Martínez, Trucco y Palma (2014), elevar los niveles educativos en la población se asocia al desarrollo, el bienestar, la productividad, la disminución de la pobreza y la desigualdad, con la construcción de la ciudadanía, la identidad y la cohesión social, de tal forma que se pueda alcanzar su inclusión social como ciudadanos. La Organización de las Naciones Unidas para la Educación, la Ciencia y la Cultura (Unesco, 1972) definió la alfabetización funcional como

el proceso de desarrollo de las capacidades básicas de lectura, escritura y cálculo que permita al individuo la participación plena en el conjunto de actividades de la persona, ya sean las del ciudadano, las del trabajador y las del individuo inserto en su familia, barrio o ciudad. En definitiva, se trata de una alfabetización que conduzca directamente a la plena autonomía del individuo (citado por Jiménez, 2005, p. 277).

Cabe señalar que el analfabetismo funcional, según Tohmé (1990), se emplea para referirse a aquellas personas que saben leer y escribir más o menos correctamente, pero que no logran extraer la comprensión para ejercer su espíritu crítico; este último término resulta limitado frente a la complejidad del desempeño implicado en la literacidad. Preferimos llamar alfabetismo disfuncional a aquel que caracteriza a las personas que aprendieron a leer y escribir como parte de su formación académica y que no emplean esas habilidades como herramientas de comunicación, participación y aprendizaje, ni realizan con eficiencia actividades que las involucran; es decir, fueron alfabetizadas, pero no emplean este desarrollo en la actuación integrada involucrando conocimientos, habilidades ni actitudes para enfrentar situaciones cotidianas que se traduzcan en formación y estas, a su vez, en calidad de vida.

\section{LITERACIDAD. LA ALTERNATIVA}

Aceves-Azuara y Mejía (2015) señalan que el individuo, hoy más que nunca, necesita contar no solo con las habilidades de lectura y escritura; también debe apropiarse 
y participar en las prácticas de literacidad pertinentes para sus diversos escenarios de vida. Las mismas autoras definen literacidad como

una práctica psico-sociocultural que incluye actitudes, conocimientos, habilidades y competencias que van más allá del dominio específico del saber leer y escribir, ya que incluye también el manejo, comprensión y producción de códigos y discursos situados social y culturalmente; los roles que asumen el lector y el autor, los valores sociales asociados con las prácticas correspondientes y las formas de pensamiento que se han desarrollado alrededor de la cultura escrita en contextos específicos [...]. La literacidad no se trata simplemente de leer y escribir diversos tipos de texto sino que se traduce en interacción con el texto y las personas para propósitos específicos en contextos particulares de uso (p. 76).

La literacidad se desarrolla interactuando con la lengua escrita y con las personas del contexto que la emplean a través de oportunidades de descubrir los convencionalismos. Leer y escribir implica, más que el conocimiento del código escrito y su descifrado mecánico, participar en diversas prácticas sociales del lenguaje que requieren la obtención de múltiples habilidades.

\section{LA ENSEÑANZA DE LA LENGUA ESCRITA A TRAVÉS DEL TIEMPO}

Al considerar la trascendencia de un aprendizaje efectivo de la lengua escrita, conviene retroceder en el tiempo y revisar las propuestas didácticas empleadas con esta finalidad, desde las más tradicionales hasta las más innovadoras. Cada una responde a una época histórica en particular, con finalidades específicas y empleando recursos disponibles en cada tiempo y lugar.

\section{Métodos de marcha sintética}

Con el Silabario de San Miguel se buscaba enseñar a leer y escribir a partir de las unidades más sencillas que se emiten en un golpe de voz: las sílabas. Esta forma la implementó la Iglesia católica para enseñar en sus escuelas en América después de la conquista, ya que, además de evangelizar, también enseñaron el castellano y a leer y escribir. Este método promovía la memorización del alfabeto, las primeras sílabas, palabras y oraciones mediante la repetición y el castigo. Se trata de un método sintético (Muñoz-Mancilla, 2017a y b).

El método alfabético o de deletreo, que se emplea desde la antigüedad, es sintético y presenta las letras a los estudiantes en orden alfabético diciendo el nombre de las letras. En este caso, los niños y las niñas tienden a deletrear al leer. Otro método es el fonético, centrado en el aprendizaje de los sonidos de las letras, que se enfoca en la pronunciación y no en el nombre de las letras. Este sistema suele ser confundido con el onomatopéyico, aunque tiene rasgos particulares. Las onomatopeyas en las que se basa son sonidos propios del ambiente del niño o la niña, y algunos de la naturaleza; por ejemplo, el llanto de la ratita: iiiiiiiiii (Torres-Quintero, 1981).

El método silábico consiste en enseñar las vocales y las consonantes para formar sílabas. Es una forma de enseñanza sintética que parte de las sílabas como unidades individuales básicas; considera que esta es la unidad más pequeña pronunciable en un golpe de voz y cada vez aborda sílabas más complejas. 
Estos métodos comparten la característica de ser sintéticos; es decir, inician enseñando las unidades más sencillas del lenguaje. Quienes aprenden con alguno de estos métodos muestran una lectura silábica, lenta y sin significado, ya que logran emplear de manera mecánica las grafías sin acceder al verdadero significado.

\section{Métodos de marcha analítica}

Ante las desventajas de los métodos de marcha sintética, surgieron propuestas con un enfoque opuesto: los métodos de marcha analítica que parten de unidades dotadas de significado; por ejemplo, el método de palabras normales o Rébsamen, que no solo tenía la finalidad de que los estudiantes conocieran los símbolos de la escritura, sino que buscaba conocimiento más amplio, que iniciaba con la observación y la exploración de objetos que, posteriormente, se presentaban como palabras que serían descompuestas en sílabas y luego serían reconocidas las letras que las integraban.

El método Minjares constituye una alternativa para la adquisición de la lengua escrita a partir de un cuento; de este nacen las oraciones que se descomponen en palabras, se descubren las sílabas de cada palabra y se presentan las llamadas carretillas que se combinan para formar nuevas palabras y enunciados. El método global de análisis estructural construyó su propuesta de enseñanza de la lectura y la escritura en torno a enunciados surgidos de ilustraciones que se descomponían en palabras, estas en sílabas y, en seguida, en letras. Este método respeta el pensamiento sincrético del niño y la niña, es ideovisual y constituye una propuesta analítica que refleja el interés por rescatar el significado.

\section{NUEVAS PROPUESTAS ALFABETIZADORAS}

En estas líneas identificamos de manera breve diferentes propuestas con las que se ha intentado enseñar a leer y escribir a los niños y jóvenes en México. Los diversos métodos buscan responder a esta necesidad, según la iniciativa y el interés de los autores, que, considerando los recursos y conocimientos disponibles sobre la adquisición de la lengua escrita del momento histórico en el que surgieron, emprendieron la tarea de enseñar a leer y escribir. Aunque con el paso de los años y los avances científicos estas formas de enseñar se han transformado, algunas continúan presentes en las aulas, a pesar de las transformaciones históricas, sociales y tecnológicas.

En las últimas décadas, han surgido nuevas propuestas y alternativas para promover el aprendizaje de la lengua escrita: el método de los veinte días, el método del nombre propio, el método Doman y la propuesta para el aprendizaje de la lengua escrita y la matemática (PALEM), entre otras, que, apoyadas en la investigación de la psicogénesis de la escritura y el constructivismo, han contribuido a una nueva visión de los procesos de aprendizaje de la lectura y la escritura.

Después de la Conferencia Mundial de Educación para Todos, se emprendieron reformas educativas basadas en un enfoque orientado al desarrollo de competencias. Desde entonces se ha introducido en planes y programas de educación básica una serie de principios que deberían conducir a la educación hacia la calidad y a alcanzar 
mejores niveles de logro, en especial en el ámbito del lenguaje, el pensamiento matemático, las ciencias y el desarrollo socioemocional. Sin embargo, el problema de la adquisición eficaz de la lengua escrita en los estudiantes continúa presente.

Hoy más que nunca es urgente revisar los procesos de enseñanza y aprendizaje en torno a la lengua escrita que se emprenden cotidianamente en las aulas, así como las prácticas docentes, los materiales utilizados y las actitudes con las que se realiza y promueve tan trascendente desarrollo para la vida de los niños.

En la actualidad, identificamos tres corrientes desde los cuales se estudian la literacidad y la alfabetización: la cognitiva, la psicogenética y la sociocultural. Estas sustentan la necesidad de cambios en relación con el aprendizaje de la lengua escrita. Desde el enfoque cognitivo, escribir es una tarea ardua que requiere el empleo de operaciones mentales complejas. Como lo refiere Caldera (2003), la escritura puede considerarse mediadora en los procesos psicológicos, ya que activa y posibilita el desarrollo de otras funciones mentales, como la percepción, la atención, la memoria y el pensamiento.

El enfoque psicogenético constituye un referente teórico para el aprendizaje de la lengua escrita al tener presente que estas son un objeto de conocimiento y el niño y la niña son el sujeto cognoscente, quien, por medio de su actividad, logrará el conocimiento. El sujeto es activo en su propio proceso de aprendizaje; compara, excluye, ordena, categoriza, reformula, construye hipótesis y ordena; en suma, se muestra como un sujeto activo intelectualmente (Ferreiro y Teberosky, 1991, 2003).

Desde el modelo sociocultural, es necesario tomar en cuenta que el contexto resulta determinante para el aprendizaje. Al respecto, Valery (2000) menciona las aportaciones de Vygotsky (1979), quien identificó los procesos psicológicos superiores que son humanos, como aquellos que tienen su origen en la vida social, que se construyen gracias a la mediación y a que interiorizan una serie de prácticas sociales e instrumentos psicológicos creados culturalmente. En el caso de la lengua escrita, es necesario un proceso de socialización concreto; es decir, se requiere un proceso de alfabetización: "La escritura aparece entonces como un instrumento psicológico que se adquiere como dominio de una práctica cultural específica” (p. 40).

En la actualidad, no se trata de un problema de cobertura, sino de valorar, revisar, reflexionar y cuestionar el quehacer docente para comprender por qué no se logran los resultados esperados en relación con la literacidad. Por ello, emprendimos este estudio cualitativo basado en un modelo de investigación-acción.

Muchas propuestas alfabetizadoras han surgido de la psicología, de la pedagogía, incluso de las neurociencias, pero pocas veces se ha considerado el espacio donde interactúan docentes y alumnos. Esta realidad es una fuente de descubrimientos que puede brindar una perspectiva que, aunque poco valorada, surge en el epicentro de la construcción del aprendizaje de la lengua escrita: el aula. Al entrar a este espacio y conocer el acontecer diario, se podrán reconocer aciertos y errores en la forma en que se aborda y fomenta el aprendizaje de la lengua escrita que, al ser identificados, permitirán reorientar la intervención de los docentes, ayudarlos a tomar mejores decisiones, elegir materiales adecuados y obtener resultados más significativos. Por ello, el problema que conduce este estudio cualitativo basado en un diseño de investigación-acción es ¿cómo se debe promover una literacidad que asegure el aprendizaje eficaz y significativo de la lengua escrita? 


\section{METOdología}

Tipo de estudio

Realizamos un estudio cualitativo basado en un diseño de investigación-acción. Hernández-Sampieri, Fernández-Collado y Baptista (2014) señalan que los estudios cualitativos no son estandarizados y que cada estudio de este tipo es único, sujeto a las condiciones del entorno y cuyo diseño utiliza aproximaciones, interpretaciones y estrategias de indagación que, a través del proceso, requerirá ciertas modificaciones. Iniciamos con la inmersión en el ambiente escolar, específicamente en aulas de primer grado del Colegio Mercedes, al ejercer la docencia como titular del grupo; aulas de preescolares y de primero de primaria de la Ciudad de México y del estado de Querétaro; como profesores de prácticas docentes en la Normal Francés Pasteur y la Normal del Instituto La Paz de Querétaro.

Si bien el trabajo fue complejo al abordar la práctica docente en todas las áreas establecidas en planes y programas oficiales (1993, 2011, 2016), recolectamos datos, estrategias e intervenciones durante varios años (veinticinco años aproximadamente), en especial aquellas relacionadas con el aprendizaje de la lengua escrita; analizamos, seleccionamos e interpretamos observaciones, actividades, comentarios, opiniones y experiencias, y a partir de ello generamos una teoría plasmada en el aprendizaje de la lengua escrita a partir de realidades integradoras.

El diseño de investigación-acción se eligió con base en la pregunta central sobre el problema de la literacidad y cómo promoverla dentro de las aulas. La alfabetización y la literacidad en la actualidad se deben considerar problemas sociales, ya que de sus alternativas y soluciones dependen aprendizajes posteriores de los niños y las niñas y, en su adultez, su participación activa como ciudadanos plenos, con derechos y obligaciones, capaces de transformar la sociedad en la que viven. Se trata de descubrir cómo resolver esta problemática y provocar un cambio en la forma de promover la adquisición de la lengua escrita de manera que permita al sujeto emplearla como herramienta de comunicación y de aprendizaje permanente.

\section{Instrumentos}

Los instrumentos empleados fueron entrevistas a docentes, planes didácticos, cuadernos de los alumnos y diario de trabajo del docente.

\section{Participantes}

-Docente frente a grupo.

-Docentes en formación bajo la tutoría de docentes experimentados.

-Alumnos de primer grado de primaria de varias generaciones que trabajaron como alumnos de la docente frente a grupo (diez generaciones de $1991 \mathrm{a}$ 1999, dos años con doble turno Colegio Mercedes, Ciudad de México). 
-Alumnos de preescolar y de primaria de los docentes en formación de escuelas públicas de la Ciudad de México y del estado de Querétaro.

-Compañeros docentes con quienes se intercambiaron puntos de vista.

\section{Procedimiento}

Fase I. Inmersión inicial en la problemática, la necesidad y su ambiente

Cuando a los docentes les confieren un grupo para trabajar al inicio del ciclo escolar, muchos de ellos no se sienten satisfechos cuando les designan tercero de preescolar o primero de primaria. ¿Por qué manifiestan inconformidad? ¿Será preocupación? Los docentes saben que su tarea principal en estos grados es que los niños aprendan a leer y escribir. Cuando se les asigna el grupo, comienzan a averiguar cómo trabajarán con los niños para lograr que salgan leyendo y escribiendo al final del ciclo escolar. Indagan con compañeros de otros grupos que ya han tenido esa experiencia y reúnen material que les comparten, comentan y proponen algunas editoriales.

En algunos casos, las escuelas ya tienen un método determinado, por ejemplo: “En esta escuela llevamos el método Minjares; ya se pidió el libro X en la lista de útiles. Yo les enseñé con el método onomatopéyico y más o menos salieron bien. Yo llevé con mis niños un método ecléctico, implementé unas fichas que encontré en internet".

Comentarios como los anteriores revelan algunas formas en que los docentes enfrentan el inicio del ciclo escolar en el que tanto padres de familia como autoridades esperan que los niños salgan leyendo y escribiendo al concluir su ciclo escolar. Con la mejor intención, inician su trabajo y se adaptan a los recursos que tienen disponibles: cuadernos, libros de texto gratuito, letras móviles, plastilina, etcétera, y sobre todo a las características de sus estudiantes, así como a aulas superpobladas, poco espacio en el salón, pizarrones maltratados y alumnos que acuden a la escuela sin el material solicitado.

Mientras transcurre el ciclo escolar, comienzan a notar quiénes van más atrasados, quiénes son los más aventajados, quiénes reciben apoyo en casa y quiénes se ausentan de la escuela con frecuencia. El docente intenta enseñar a leer y escribir a su alumnado de manera eficiente y, simultáneamente, debe desarrollar el pensamiento matemático, cubrir los programas de las demás asignaturas, atender el desarrollo socioemocional, así como diversos imprevistos que se presentan diario en el aula; participar en las actividades que organiza la propia escuela y en las convocadas por otras instituciones y llenar una serie de documentos. Los docentes ven su jornada reducida e insuficiente para lograr un dominio de la lengua escrita en sus alumnos.

En estas circunstancias, ¿en verdad se obtendrá un aprendizaje significativo y eficaz de la lectura y la escritura? Con estas prácticas, ¿se desarrollará la literacidad?

Fase 2. Recolectar datos sobre la problemática y las necesidades vinculadas a esta

Es necesario recordar que, tradicionalmente, una persona alfabetizada es la que sabe leer y escribir. En la actualidad, esta idea implica nuevos retos: dominar diversos lenguajes; adquirir capacidades lingüísticas; comprender numerosos tipos de 
texto; expresar ideas y pensamientos propios por medio de la escritura; y enfrentar situaciones comunicativas empleando tanto el lenguaje oral como el escrito en sus distintas modalidades y con diferentes fines.

Los docentes que asumen el reto de enseñar a leer y escribir eligen un método con características particulares que aportan ventajas y desventajas al proceso de aprendizaje de los niños. Seleccionan actividades y estrategias, valoran algunas positivamente y otras las descartan; muchas veces, tal decisión depende de la personalidad y las experiencias previas del docente. Hay profesores que eligen lo que han realizado durante años, lo que tiene cierta fama entre la comunidad docente o lo que les da certeza y seguridad al replicar lo que ya ha mostrado ciertos logros.

De esta forma, conviene revisar los métodos más utilizados, las estrategias de las que se valen los docentes, así como los materiales y recursos que apoyan a cada uno, e identificar qué tipo de aprendizaje se desarrolla en sus estudiantes como resultado de su intervención en el aula. Para ello, será conveniente tener presente que leer no solo es descifrado ni se limita a poseer la capacidad de sonorizar un texto: es construir significados, y escribir no es copiar un modelo, sino expresar ideas, pensamientos, sentimientos y necesidades por medio de signos gráficos, lo que es diferente a saber trazar letras.

Tabla 1. Métodos tradicionales empleados por los docentes para alfabetizar

\begin{tabular}{|c|c|c|c|}
\hline Método & Características & Ventajas & Desventajas \\
\hline $\begin{array}{l}\text { Alfabético o de } \\
\text { deletreo }\end{array}$ & $\begin{array}{c}\text { Sintético } \\
\text { Primero se enseñan las letras } \\
\text { en orden alfabético; poste- } \\
\text { riormente combinaciones } \\
\text { (Barbosa-Heldt, 1971) }\end{array}$ & $\begin{array}{l}\text { Atiende la entonación, } \\
\text { las pausas y los signos de } \\
\text { puntuación } \\
\text { Cuida la forma }\end{array}$ & $\begin{array}{c}\text { Es lento } \\
\begin{array}{c}\text { Genera confusión al conocer } \\
\text { primero los nombres } \\
\text { de las letras }\end{array} \\
\text { Fomenta lectura mecánica } \\
\text { No atiende la comprensión } \\
\text { del significado del texto } \\
\text { Se deletrea al leer }\end{array}$ \\
\hline Fonético & $\begin{array}{c}\text { Sintético } \\
\text { Se centra en el aprendizaje de } \\
\text { los sonidos de las letras } \\
\text { Destaca la pronunciación } \\
\text { (Guevara-Cuadrón, 2005) }\end{array}$ & $\begin{array}{c}\text { Es simultáneo. Se aprende } \\
\text { a leer y a escribir al mismo } \\
\text { tiempo } \\
\text { Evita el deletreo }\end{array}$ & $\begin{array}{l}\text { Contradice los procesos men- } \\
\text { tales del aprendizaje } \\
\text { Logra una lectura mecánica }\end{array}$ \\
\hline Onomatopéyico & $\begin{array}{c}\text { Sintético-analítico } \\
\text { Se basa en onomatopeyas } \\
\text { (sonidos propios del ambien- } \\
\text { te del niño) (Torres Quintero, } \\
\text { 1981) }\end{array}$ & $\begin{array}{l}\text { Agradable y novedoso } \\
\text { para los niños al vincular } \\
\text { las onomatopeyas con un } \\
\text { cuento } \\
\text { Es simultáneo } \\
\text { Propone el empleo de dife- } \\
\text { rentes materiales de apoyo }\end{array}$ & $\begin{array}{l}\text { Solo maneja la letra script } \\
\text { Asociar ideas a onomatope- } \\
\text { yas dificulta la comprensión } \\
\text { de la lectura (Rodríguez, } \\
\text { 2007) }\end{array}$ \\
\hline Silábico & $\begin{array}{c}\text { Sintético } \\
\text { Consiste en enseñar las } \\
\text { vocales y consonantes para } \\
\text { formar sílabas } \\
\text { Parte de las sílabas como } \\
\text { unidades más pequeñas }\end{array}$ & $\begin{array}{c}\text { Evita el deletreo, al } \\
\text { enfocarse en las sílabas } \\
\text { Logra una lectura ágil y } \\
\text { rápida } \\
\text { Es económico }\end{array}$ & $\begin{array}{l}\text { Los niños silabean al leer } \\
\text { Lento y sin significado } \\
\text { Logran emplear mecánica- } \\
\text { mente las grafías sin acceder } \\
\text { al significado }\end{array}$ \\
\hline
\end{tabular}


Como apreciamos en la tabla 1, los métodos revisados coinciden en un proceso que surge a partir de las unidades más sencillas del lenguaje y en el cual carecen de significado la letra o la sílaba. Al elegir alguno de estos métodos tradicionales, enfoca su atención en el descifrado y logra un desarrollo mecánico. El único que busca dar significado al tomar la letra con base en los sonidos de la naturaleza es el onomatopéyico. Sin embargo, es necesario conocer las onomatopeyas porque, frecuentemente, confunden este método con el fonético. Un gran número de docentes indicó estar empleando el método onomatopéyico, pero en realidad hacían hincapié en el sonido de las letras; por ejemplo, la R de ratita, lo que es un error, ya que al llanto de la ratita le corresponde la onomatopeya iiiiiiiii, de la letra i, no la R.

El trabajo con el método elegido por el docente se realiza al margen de los planes y programas de la asignatura de español o del campo formativo de lenguaje y comunicación. Por ello, llevan libros de apoyo en algunos casos de línea editorial o actividades impresas de sílabas, letras, incluso planas en un cuaderno. De esta forma, el aprendizaje de la lengua escrita se separa, y se atiende de manera aislada el enfoque comunicativo y funcional que debe caracterizar el trabajo en el aula. Al repetir los modelos enseñados por el profesor, el niño o la niña no tienen oportunidad de ser un agente activo en su proceso de aprendizaje; dependen del orden y las estrategias del docente.

Otros profesores toman decisiones con la finalidad de facilitar el aprendizaje de la lengua escrita; por ejemplo, solo enseñar las letras mayúsculas, porque consideran que así es más fácil que aprendan los niños; otros piensan que únicamente se debe enseñar la letra script, porque la cursiva ya no se usa; otros incluso van letra por letra: la presentan con su nombre y la trazan en su cuaderno, pero sin referencia alguna a un objeto o nombre que les permita relacionarlas.

En algunos casos se pide a los niños que realicen trazos y que escriban como puedan y no se ayuda a reconocer ni a identificar ciertos convencionalismos del lenguaje escrito; se utilizan cuadernos de raya para trazar letra script y cuadernos de cuadro para trazar letra cursiva; se enfocan en el error y este es señalado con rigor; no con paciencia ni con la consideración de que es una oportunidad para aprender.

Como apreciamos, en estas experiencias no se promueve la literacidad. Se enseña a leer y a escribir de forma artificial, mecánica y desvinculada de la realidad.

Fase 3. Un plan de acción alternativo, más actual, objetivos, estrategias y recursos. Recolectar datos adicionales

El problema identificado inicialmente permitió que los docentes optaran por alternativas más innovadoras. Prefirieron los métodos analíticos, que consideran importante que el niño y la niña construyan su aprendizaje a partir de unidades del lenguaje dotadas de significado, textos, imágenes, oraciones o palabras. Estos métodos se muestran en la tabla 2 . 
Tabla 2. Métodos analíticos

\begin{tabular}{|c|c|c|c|}
\hline Método & Características & Ventajas & Desventajas \\
\hline Palabras normales & $\begin{array}{c}\text { Analítico-sintético } \\
\text { Fonético, simultáneo, } \\
\text { ecléctico (Barbosa-Heldt, } \\
\text { 2004) }\end{array}$ & $\begin{array}{l}\text { Buscaba que los alumnos } \\
\text { conocieran las cosas, más } \\
\text { que los símbolos de la } \\
\text { escritura }\end{array}$ & $\begin{array}{c}\text { Vocabulario ajeno a las } \\
\text { nuevas generaciones } \\
\text { Promueve la lectura } \\
\text { mecánica }\end{array}$ \\
\hline $\begin{array}{l}\text { Global de análisis } \\
\text { estructural }\end{array}$ & $\begin{array}{c}\text { Orienta la enseñanza } \\
\text { de la lectura y escritura } \\
\text { a partir del enunciado; } \\
\text { luego se va a las palabras, } \\
\text { sílabas y letras } \\
\text { Es de marcha analítica } \\
\text { Es ideovisual }\end{array}$ & $\begin{array}{c}\text { Respeta la percepción } \\
\text { sincrética del niño } \\
\text { Se presentan ideas } \\
\text { completas sin mostrar } \\
\text { elementos aislados } \\
\text { Favorece la } \\
\text { pronunciación correcta } \\
\text { Es simultáneo } \\
\text { Se basa en la enseñanza } \\
\text { activa } \\
\text { Busca lograr la } \\
\text { comprensión }\end{array}$ & $\begin{array}{l}\text { Solo maneja la letra } \\
\text { script } \\
\text { Es lento al implicar el } \\
\text { conocimiento de las } \\
\text { palabras como unidades } \\
\text { diferentes entre sí } \\
\text { Requiere mucho apoyo } \\
\text { del docente; si no se } \\
\text { le brinda, varios niños } \\
\text { podrán rezagarse }\end{array}$ \\
\hline Minjares & $\begin{array}{c}\text { Analítico-sintético y } \\
\text { sintético-analítico } \\
\text { Es global } \\
\text { El niño aprende a expre- } \\
\text { sar ideas de acuerdo con } \\
\text { las letras que identifica a } \\
\text { partir del cuento } \\
\text { Emplea la técnica } \\
\text { LIDAPLA }\end{array}$ & $\begin{array}{l}\text { Requiere trabajar } \\
\text { actividades de } \\
\text { maduración } \\
\text { Permite al niño leer y } \\
\text { escribir en poco tiempo }\end{array}$ & $\begin{array}{l}\text { Empleo de carretillas (se- } \\
\text { ries de sílabas), ya que } \\
\text { si el maestro no las lee } \\
\text { correctamente, los niños } \\
\text { van a silabear al leer } \\
\text { Espacios reducidos en } \\
\text { sus libros para contestar } \\
\text { Las oraciones que se } \\
\text { forman pueden ser } \\
\text { artificiales }\end{array}$ \\
\hline Doman & $\begin{array}{c}\text { Es interactivo. } \\
\text { Considera los bits de } \\
\text { inteligencia tal como } \\
\text { funcionan los } \\
\text { ordenadores }\end{array}$ & $\begin{array}{l}\text { Permite que los niños } \\
\text { se familiaricen con los } \\
\quad \text { signos gráficos } \\
\text { Puede ser útil implemen- } \\
\text { tarlo antes de que el niño } \\
\text { ingrese a la escuela } \\
\text { Estimula a los niños } \\
\text { visual y lingüísticamente } \\
\text { y los familiariza con los } \\
\quad \text { signos gráficos }\end{array}$ & Se orienta a la lectura \\
\hline De los 20 días & Sintético & Rapidez y eficiencia & $\begin{array}{l}\text { Se basa en la memoriza- } \\
\text { ción de sílabas } \\
\text { Desarrolla un dominio } \\
\text { mecánico y alejado del } \\
\text { significado }\end{array}$ \\
\hline Del nombre propio & $\begin{array}{c}\text { El nombre propio es la } \\
\text { palabra generadora de } \\
\text { identidad personal y de } \\
\text { aprendizaje } \\
\text { Propuesta analítica y } \\
\text { lúdica }\end{array}$ & $\begin{array}{c}\text { Busca atender las funcio- } \\
\text { nes del lenguaje escrito y } \\
\text { de las letras, así como el } \\
\text { significado de la lectura } \\
\text { Cuida los trazos } \\
\text { correctos }\end{array}$ & $\begin{array}{l}\text { Al emplear los nombres } \\
\text { de compañeros, fami- } \\
\text { liares y apellidos limita } \\
\text { la escritura de otras } \\
\text { palabras }\end{array}$ \\
\hline
\end{tabular}

Los docentes que optan por el método global de análisis estructural tienden a desanimarse porque, al trabajar con un solo enunciado a la vez, el tiempo de enseñanza se prolonga antes de que los niños puedan combinar palabras para formar nuevas 
oraciones. A través del método Minjares, se brinda al niño la posibilidad de escribir oraciones y leerlas desde la segunda unidad. Las oraciones son limitadas a las palabras aprendidas a partir del cuento, aunque crean palabras nuevas con el juego del mago en el que combinan carretillas (series de sílabas, por ejemplo: ma, me, mi, mo, $\mathrm{mu}$ ) que se colocan en un tablero.

Los maestros que optan por el método de los 20 días descargan el material de la red y trabajan con las láminas siguiendo las instrucciones para enseñar a leer y escribir en poco tiempo; sin embargo, se logra una lectura mecánica. Los docentes que desean enseñar a leer y escribir desde los primeros años del preescolar eligen el método Doman, que busca familiarizar a los niños con las palabras; se considera como una forma de estimulación temprana. Por su parte, los docentes que eligen el método del nombre propio realizan diversas actividades para que los niños aprendan a escribir su nombre.

Lo que pudimos reconocer en el empleo de estos métodos es que los docentes los aplican sin un conocimiento amplio de la forma en que debe trabajarse cada uno, y no siguen las indicaciones de los autores; muchas veces, al desconocer sus propuestas, desvirtúan sus propósitos y terminan trabajando fonemas, sílabas, incluso enseñando las letras por su nombre, adoptando y combinando actividades de varios métodos. El factor común que sigue presente en este tipo de promoción del aprendizaje de la lengua escrita es que se busca que el niño y la niña identifiquen las letras, pero no se está favoreciendo un aprendizaje que le permita un dominio de ambas herramientas de comunicación y aprendizaje.

Entre las prácticas que reconocimos en el trabajo en las aulas con la finalidad de enseñar a leer y escribir, podemos señalar el dictado de sílabas, letras, palabras y, en casos más avanzados, oraciones; el empleo de las letras móviles, masas y plastilina, recipientes con gel o con harina para trazar las letras; colorear sílabas o letras con una clave para encontrar dibujos; seguir las letras del abecedario para formar figuras, recortar letras, sílabas o palabras con determinadas letras y pegarlas en el cuaderno; y la impresión de cuadernillos de letras o sílabas que se descargan de internet y se resuelven como actividades de apoyo. El fenómeno sigue siendo que se enseña a descifrar las letras; no a leer y a trazar letras ni tampoco a expresar.

Los libros de texto gratuitos presentan algunas actividades que no coinciden con los métodos empleados por los docentes; están orientados a un enfoque de prácticas sociales del lenguaje, e incluyen proyectos, juegos y materiales para facilitar el intercambio de ideas entre compañeros. Sin embargo, en muchas ocasiones se dejan de tarea en casa y los niños no tienen la oportunidad de desarrollar habilidades para interrelacionarse con sus pares; si tienen suerte lo harán con los adultos y otros miembros de su familia. Otros menos afortunados no realizarán las tareas y quedarán privados de las oportunidades de aprender de sus compañeros y de otras personas.

Debido a la preocupación por los bajos niveles de comprensión lectora y las escasas habilidades para expresarse por medio de la escritura, se invitó a los docentes a capacitarse en la propuesta PALEM. Sin embargo, esta capacitación no llegó a todos los docentes para quienes sería una excelente alternativa para favorecer un aprendizaje eficaz de la lengua escrita. Gómez Palacio et al. (1982) presentaron esta 
propuesta integrada en fichas clasificadas en actividades individuales, en equipo y grupales, así como otras que podrían llevarse a cabo como tarea en casa.

Esta metodología incluyó actividades para apoyar el aprendizaje de los niños y tomó en cuenta los niveles de conceptualización alcanzados. Lamentablemente, esta propuesta solo fue conocida por un número reducido de docentes y, a pesar de estar conformada por actividades orientadas al desarrollo de la literacidad, no se pudo extender ni concretar en el trabajo de las aulas. Años más tarde, muchas actividades incluidas en la propuesta PALEM se integraron a los ficheros de la Secretaría de Educación Pública (SEP, 1993, 1997a y b) y, aunque estaban a disposición de los docentes, estos en muchos casos no los aprovecharon.

Algunos maestros expresaron que no hay tiempo suficiente para la realización de actividades lúdicas durante la jornada. Determinan e identifican los niveles de conceptualización de los niños por medio de dictados y lectura sugeridos en la propuesta, pero no se implementan las actividades que brindarían a los niños la posibilidad de transitar en su proceso de aprendizaje ni se les cuestiona para ayudarlos a reflexionar y a formular nuevas hipótesis.

Fase 4. Determinar las características de un método orientado al desarrollo de la literacidad

Es evidente que, aun cuando han surgido alternativas para apoyar a los docentes a emprender procesos de alfabetización y lograr a través de ellos una alfabetización funcional, no todos los profesores han tenido la oportunidad de conocerlas, porque los cambian de grado o las editoriales, pese a que brindan una capacitación para que se empleen sus libros en el aula, en muchos casos se trata de métodos que, aunque tienen imágenes atractivas, la realidad en cuanto a la lengua escrita sigue siendo desalentadora.

No podemos señalar a un solo responsable; es claro que se trata de un problema multifactorial que debe revisarse $\mathrm{y}$, al reconocer aquellos aspectos que resultan indispensables y que no han sido tomados en cuenta, deberán considerarse en una alternativa viable que tenga claro el objetivo de favorecer el desarrollo de la literacidad por medio de una serie de acciones, recursos e intervenciones que puedan asegurarlo.

En este sentido, los aspectos que deben considerarse y que fueron identificados mediante las fases anteriores de nuestro estudio, y a partir de las cuales diseñaremos un plan de intervención, son:

- Buscar un acercamiento de los niños a la lengua escrita a partir de lo que ellos conocen.

-Evitar el trabajo de unidades aisladas del lenguaje para promover su aprendizaje.

-Animar el vocabulario y promover el desarrollo de las competencias comunicativas.

-Promover la construcción de significados y la comprensión en general. 
-Ampliar las experiencias del niño y la niña.

-Enriquecer la cultura del niño y la niña.

- Permitir y promover la expresión y el intercambio de ideas.

- Reflexionar sobre las actitudes necesarias en el docente que pueden facilitar u obstaculizar el aprendizaje del niño y la niña.

-Hacer que el aprendizaje sea una experiencia grata.

- Tomar en cuenta las necesidades y características del niño y la niña, así como su proceso evolutivo.

-Diversificar el tipo de estrategias.

-Promover la reflexión.

- Buscar que sea económico y de fácil manejo.

- Fomentar la participación del niño y la niña en situaciones comunicativas.

-Facilitar el aprendizaje de la lengua escrita a través del empleo del lenguaje en toda su riqueza y complejidad.

-Favorecer la producción y la comprensión de textos con diferentes finalidades y modalidades.

A partir del reconocimiento de los aspectos que deberán ser tomados en cuenta, procedimos a diseñar un proyecto de intervención.

Fase 5. Diseñar un plan de acción. Toda la experiencia se integra en el aprendizaje de la lengua escrita a partir de realidades integradoras que surge de la aplicación del método MAPRI (método de alfabetización a partir de realidades integradoras).

El método de alfabetización a partir de realidades integradoras surgió de una experiencia de investigación-acción efectuada en aulas de preescolar y primaria a través de la interacción con alumnos y docentes, observación, registro de experiencias, análisis e integración. El resultado se concreta en un método conformado por cuatro materiales: un libro de grafomotricidad (para segundo de preescolar), un libro de actividades para tercero de preescolar, un libro de actividades para primero de primaria, un libro-manual para el maestro y una colección de juegos de mesa.

Los materiales se diseñaron en torno a realidades integradoras vinculadas a la vida del niño: la escuela, la familia, el lugar donde vivo, me alimento, me quiero, me cuido y me arreglo, cuido el ambiente, el día y la noche, las plantas, los animales y las vacaciones.

Cada realidad integradora contiene actividades diversas que le permiten al niño y a la niña familiarizarse con los convencionalismos del lenguaje. El tratamiento en cada grado escolar es diferente; se busca respetar su desarrollo evolutivo. Por ello se inicia mediante la grafomotricidad; posteriormente, se manejan situaciones comunicativas relacionadas con cada realidad integradora. En segundo y tercero de preescolar se trata de las realidades integradoras: la escuela, 
la familia, el lugar donde vivo, me alimento, me quiero, me cuido y me arreglo, y en primero de primaria: cuido el ambiente, el día y la noche, las plantas, los animales y las vacaciones.

En cada página, al calce, se incluye una serie de cuestionamientos y pautas para que el docente intervenga y, de esta forma, favorezca la expresión oral de sus alumnos, que, progresivamente, también será escrita. Al finalizar cada unidad, se participa en un juego de mesa que retoma el vocabulario de la unidad y contribuye a la interacción entre compañeros.

La intervención del docente con una actitud paciente, asertiva y entusiasta es importante para guiar la reflexión y conducir las actividades propuestas. Así se lleva paso a paso al niño a la construcción de significados vinculados a cada realidad integradora, ya que, como lo menciona Carretero (2002), "la construcción que elaboramos todos los días, y en casi todos los contextos en los que se lleva a cabo nuestra actividad, depende de dos aspectos: de la representación inicial que tengamos de la nueva información, y de la actividad, externa o interna, que desarrollemos al respecto" (p. 25).

Este método también se basa en la teoría de Ausubel (Viera-Torres, 2003) sobre el aprendizaje significativo, de ahí que se presenten al niño y a la niña las realidades integradoras, porque estas significan para ellos la oportunidad de aprender a partir de lo que conocen; al aprender a leer y escribir, irán realizando aproximaciones simultáneas (Lerner, 2001) que implican para el infante modificar sus estructuras cognitivas gracias a la oportunidad de contrastar sus ideas y experiencias con las de los demás. También se le brinda a través del material que está organizado de forma coherente y estructurada con base en lo que conoce.

Para diseñar los materiales, tomamos en cuenta los niveles de elaboración verbal (Amestoy, 1999):

-Palabra y significado (relación simple): pidiendo al niño o a la niña que, al ver una palabra, imagine, dibuje y represente.

-Agrupamientos: relacionando palabras con un elemento en común a través de campos.

-Categorizaciones: por medio de relaciones de palabras que refieren conceptos abstractos.

-Inferencias simples: lograr interpretaciones o argumentaciones.

Los materiales han sido diseñados cuidadosamente y con las consideraciones expresadas y detalladas en este estudio; se están elaborando los prototipos correspondientes a cada material, incluyendo las actividades aplicadas en cuadernos de los alumnos de los participantes y, gracias al apoyo de las escuelas, se encuentra en la fase piloto, en la que empleamos los prototipos, aunque debido a la pandemia de la COVID-19 tuvo que posponerse. 


\section{CONCLUSIONES}

El reconocer y reproducir letras no implica conocer el funcionamiento del sistema de escritura. Por ello, es indispensable que los niños conozcan los signos gráficos, así como sus reglas de uso mediante situaciones que les permitan valorar la escritura y la lectura como herramientas de comunicación y aprendizaje. Esto último será posible gracias al trabajo constante, dinámico y reflexivo a través de la revisión de las realidades integradoras propuestas y las actividades sugeridas para desarrollar en cada caso. El trabajo con la lectura y la escritura será más eficiente si las palabras tienen una relación entre sí y forman parte de la realidad del niño y la niña.

El método producto de este proceso de investigación-acción tiene como características:

- Conducir al niño y a la niña, mediante el trabajo interactivo que se realice en el aula, a apropiarse de la realidad por medio de las estrategias y los materiales, y propiciar la reflexión, así como ejemplificar y compartir experiencias para favorecer el desarrollo de conocimientos, habilidades y actitudes en relación con la lengua escrita.

-Simultáneamente, brindar la oportunidad de descubrir los elementos y las características del lenguaje escrito mientras los utilizan.

-Fomentar el desarrollo del leguaje desde una visión integral y las competencias comunicativas mediante su participación en situaciones de intercambio y comunicación de ideas; es decir, atendiendo el aspecto productivo y comprensivo del lenguaje.

-Promover la interacción lúdica entre pares.

- Impulsar procesos metacognitivos para ayudar al niño y a la niña a desarrollar autorregulación en su comportamiento y actividades de aprendizaje.

El método MAPRI permite que la experiencia de aprendizaje sea continua, dinámica, vinculada a la realidad del niño y la niña y lúdica, por lo que, al alcanzar un mayor grado de significatividad en su aprendizaje, mayores serán las probabilidades de que empleen la lengua escrita de manera eficiente en todos los ámbitos de sus vidas, y logren una transferencia a nuevas situaciones. Al interactuar con otras personas, ya sean sus pares o adultos, participan en actividades y situaciones comunicativas, se les ayuda a concentrarse y a escuchar; de esta forma, establecerán conexiones a partir de la información que reciben. Les permitimos comprender el mundo que los rodea y construir significados. Como señala Fox (2007):

Las palabras son esenciales para establecer conexiones correctas en el cerebro, cuanto más lenguaje experimenta un niño [...] más aventajado se verá desde el punto de vista social y educativo durante toda su vida. Y a la inversa, cuantas menos palabras experimente, aprenda y utilice más entumecido estará su cerebro [p. 30].

Ferreiro (1997) invita a los docentes a pensar sobre su quehacer en torno a la enseñanza de la lectura y la escritura:

En lugar de preguntarnos si debemos o no debemos enseñar, hay que preocuparnos por dar a los niños ocasiones de aprender. La lengua escrita es mucho más que un conjunto 
de formas gráficas. Es un modo de existencia de la lengua, es un objeto social, es parte de nuestro patrimonio cultural [p. 6].

Las nuevas generaciones enfrentan una realidad global que les demanda una serie de habilidades que, en conjunto, les permitirán participar como ciudadanos del mundo. Por ello, no se trata únicamente de lograr que lean y escriban con eficiencia, sino de favorecer la literacidad para estar a la altura de las circunstancias. Les exigirá desarrollar el pensamiento crítico y ser competentes para salir adelante en un mundo que es incierto y complejo.

\section{REFERENCIAS BIBLIOGRÁFICAS}

Aceves-Azuara, I. y Mejía-Arauz, R. (2015). El desarrollo de la literacidad en los niños. Recuperado de rei.iteso.mx/handle/11117/3026?show=full

Amestoy de Sánchez, M. (1999). Desarrollo del pensamiento. Planifica y decide. México: Trillas.

Barbosa-Heldt, A. (2004). Cómo enseñar a leer y escribir. México: Pax.

Barbosa-Heldt, A. (1971). Cómo han aprendido a leer y a escribir los mexicanos. México: Pax.

Caldera, R. (2003). El enfoque cognitivo de la escritura y sus consecuencias metodológicas en la escuela. Educere, vol. 6, núm. 20, pp. 363-368. Recuperado de https://n9.cl/x2bu

Carretero, M. (2002). Constructivismo y educación. México: Progreso.

Ferreiro, E. (1997). Alfabetización. Teoría y práctica. México: Siglo XXI Editores.

Ferreiro, E. y Teberosky, A. (2003). Los sistemas de escritura en el desarrollo del niño. México: Siglo XXI Editores.

Ferreiro, E. y Teberosky, A. (1991). La teoría de Piaget en relación a aprendizaje de la lectura y la escritura. Quehacer Educativo, vol. 1, núm. 1, pp. 9-11. Recuperado de https://n9.cl/5tbsh

Fox, M. (2007). Leer como por arte de magia. Buenos Aires: Paidós.

Gómez-Palacio, M., Cárdenas, M., Guajardo, E., Kaufman, A. M., Laura, M., Maldonado, M., Richero, N. y Velázquez, I. (1982). Propuesta para el aprendizaje de la lengua escrita. México: Secretaría de Educación Pública.

Guevara-Cuadrón, O. J. (2006). Enseñanza para la lecto-escritura. Recuperado de https://n9.cl/0enp

Hernández-Sampieri, R., Fernández-Collado, C. y Baptista Lucio, P. (2014). Metodología de la investigación. México: McGraw-Hill.

Jiménez del Castillo, J. (2005). Redefinición del analfabetismo: el analfabetismo funcional. Revista de Educación, núm. 338, pp. 273-294. Recuperado de https://n9.cl/gvmt

INEE (2019). Informe de resultados Planea. Educación básica. Recuperado de https://n9.cl/x0ly

INEE (2015). Planea: una nueva generación de pruebas. ¿Qué evalúan las pruebas? Lenguaje y comunicación. Fascículo 7. México.

Lerner, D. (2001). Leer y escribir en la escuela, lo real, lo posible y lo necesario. México: Fondo de Cultura Económica/Secretaría de Educación Pública. 
Martínez, R., Trucco, D. y Palma, A. (2014). El analfabetismo funcional en América Latina y el Caribe. Panorama y principales desafíos de política. Naciones Unidas. CEPAL. Serie Políticas Sociales, núm. 198, pp. 1-42. Recuperado de https://n9.cl/x6f4

Muñoz-Mancilla, M. (2017a). Evolución de los procesos de alfabetización: de silabarios a prácticas sociales del lenguaje. Tra $H s, 2$. La alfabetización inicial en espacios escolarizados y no escolarizados en América Latina y África. Recuperado de https://n9.cl/vz4k

Muñoz-Mancilla, M. (2017b). La enseñanza de la lecto-escritura en México: evolución de métodos memorísticos a procesos de aprendizaje. Revista de Estudios Clínicos e Investigación Psicológica, vol. 7, núm. 13, pp. 47-58. Recuperado de https://n9.cl/ck3j

OCDE (2018). Programa para la Evaluación Internacional de Alumnos (PISA). Resultados. Recuperado de https://n9.cl/1eczm

Rodríguez-Álvarez, M. A. (2007). Rébsamen versus Torres Quintero. Dos métodos de lecto-escritura que rivalizan en México durante el siglo XX. En Memoria III Foro Colima y su Región. Arqueología, antropología e historia. Colima, México: Gobierno del Estado de Colima, Secretaría de Cultura.

SEP (1997a). Curso-taller Estrategias metodológicas para la comprensión de textos de $1^{o}$ a $6^{o}$ grados. PALEM-PRONALEES. México.

SEP (1997b). Curso-taller La consolidación de los componentes del español en educación primaria. PALEM/PRONALEES. México.

SEP (1993). Plan y programas de Educación Básica. Primaria. México: Secretaría de Educación Pública.

Tohmé, G. (1990). Universidad y alfabetización. En H. S. Bhola (coord.). Cuestiones sobre alfabetización. Barcelona: Unesco/Organización Internacional para la Educación de Cataluña.

Torres-Quintero, G. (1981). Método onomatopéyico. México: Patria.

Unesco (s.f.). Alfabetización. Recuperado de https://n9.cl/30az

Viera-Torres, T. (2003). El aprendizaje verbal significativo de Ausubel. Algunas consideraciones desde el enfoque histórico cultural. Universidades, vol. 26, pp. 37-43. Recuperado de https://n9.cl/xedy

Valery, O. (2000). Reflexiones sobre la escritura a partir de Vygotsky. Educere, vol. 3, núm. 9, pp. 38-43. Recuperado de https://n9.cl/x4j2 